\title{
EDITORIAL:
}

\section{Fostering Cultural Awareness}

This edition of Refuge brings us once again to the human scale of Canada's commitment to refugees as we present the second report on the Host Family Program. This program, inaugurated early in 1985 , is a "Canadian original." It is designed to provide a more personalized introduction to life in Canada for government-assisted refugees, especially those arriving in families, single female or singie male household heads, and others with special needs.

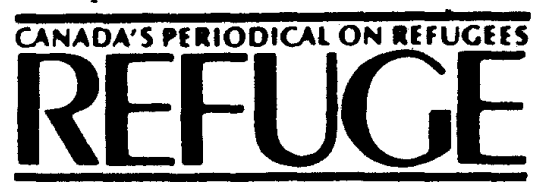

c/o Refugee Documentation Project, York University 4700 Keele Street, North York, Ontario M3N 1 P3

\section{Editor: \\ C. Michael Lanphier \\ Managing Editor: \\ Noreen Spencer-Nimmons \\ Assistant Managing Editor: \\ Joan Atlin}

Refuge is dedicated to the encouragement of assistance to refugees by providing a forum for sharing information and opinion on Canadian and international issues pertaining to refugees. It is published four times a year by the Refugee Documentation Project. It is a non-profit, independent periodical supported by private donations and by subscriptions. It is a forum for discussion, and the views expressed do not necessarily reflect those of its funders or staff.

All materials in Refuge may be reproduced without permission unless copyrighted or otherwise indicated. Credit should be given to the author or source, if named.

Subscription rates for one year are $\$ 20.00$ in Canada and US $\$ 25.00$ elsewhere. Please enclose payment with your order.

Logo design:

Dreadnaught Co-operative Inc. Toronto

Produced by

Department of Communications,

York University.

Second Claw Matl Regiwration $N_{11}$ 551: ISSN 0299-5113
The Host Family Program is a pilot project shared between the private sector and government. It has been criticized for possibly draining away volunteers from private sponsorship, thus reducing the number of private sponsorships. Others criticize the program for subsidizing an undertaking which they believe should be fully the federal government's responsibility.

The criticisms are misdirected. If anything, the spontaneous comments of representatives of host families are infused with the same spirit of generosity as shown by the volunteers who form the backbone of this program. The enthusiasm from the Host Family Program has already served as a catalyst for sponsorships.

By making contacts with a wide number of local church and other organized community groups, the program has widened the network of groups for recruitment both of host families and private sponsors. As the degree of financial and personal commitment is lighter on individuals, the Host Family Program allows a group to "try out" an experience of contact with newcomers. The results to date indicate that hosts not only feel that they have benefited greatly, but they tell others about this experience. Private sponsorship could have no better publicity agent.

Government circles may justify the Host Family Program on the basis of lowering the cost and spreading the responsibility for government-assisted refugees. Yet the cost "savings" are not great, in comparison with costs sustained for government-assisted refugees without host family experience. The reasons are close at hand: the genius of the Host Family Program is in fostering Canadian cultural awareness. This extends from better and wider acquaintance with English and French language and expression, and by becoming avid consumers in the development of networks of friends and acquaintances among established Canadians.

And the cultural awareness is reciprocal 'Host family groups themselves develop cultural sensitivities which cannot be communicated in TV documentaries or classroom drill. They share the swings of elation and despair, and of the hope and grim reality which fill the first few months of a newcomer's life in Canada. Most of all, they realize that life experiences are common, however tightly bound in different cultural wrappings. As a program, there are still some uncertainties in the Host Family Pilot Project: (1) will the program be as successful in large metropolitan areas with a wide variety of organizations, each with its own reporting line and responsibilities; and, (2) will the promise of spreading the interest in helping the newcomer refugees be realized in the private sector?

While this report points to positive replies, it is clear that the Host Family Program is being evaluated as a government project which has to show not only that specified objectives have been accomplished, but that they have been cost effective as well. The last word is still to come.

\section{Michael Lanphier, Editor}

\section{$\diamond$}

\section{Forthcoming}

FORCED TO FLEE: Resources on Refugees and Development Canadian Jesuit Centre. An educational kit which focuses on refugees and development. Contains a User's Guide, "Forced to Flee, A Refugee Story..." Getting Started; Media; Women at Risk; Waiting for a Miracle; "When Someone Asks" and suggestions for action. Due for September 1988 publication. Anticipated price is $\$ 10$ plus $\$ 2$ postage. Canadian Jesuit Refugee Programme, 947 Queen Street East, Toronto, Ontario, M4M $1 \mathrm{~J} 9$.

REFUGEES in POLICY and PRACTICE: Report of the Seminar Series.

Written by Robert Kreklewich and Noreen Spencer-Nimmons, the document reports on the 1986-1987 and the 1987-1988 proceedings. North York: Refugee Documentation Project. Twenty plus pages, desk-top copy, \$Can 5.00, postage not included. 
Host Family Update.... Cont'd from page 1

couver. The sample from Quebec City consists only of host-group refugees due to the problem of having no control group. Therefore, data for Quebec City are sometimes discussed separately, where necessary.

\section{Sample Selection}

In each of the six cities, Kitchener, London, Winnipeg, Regina, Calgary and Vancouver the CEC (Canada Employment Centre) created sample groups of 35 host-group refugees and 35 control group refugees (see Table 1). Refugees in the control group portion of the sample were selected from government-assisted refugees who arrived during the same time period as those in the host group. Both sample groups were eligible to receive all the services normally provided to government-assisted refugees in the community.

\section{Indicators of Social Adaptation}

\section{Accommodation}

Most refugees, whether host group or control group, moved into permanent accommodation within the first week in several communities. In Quebec City, Vancouver, and especially Kitchener, the process of finding permanent accommodation took somewhat longer; for example, half of all Kitchener refugees were unable to find permanent accommodation until well after a month had elapsed. Only in Vancouver were host groups effective in finding accommodation for their refugees. In all other communities, either CEC or a mix of other agencies assisted in finding suitable housing.

TABLE 1 - $\quad$ Host Program Pilot Projects: 1985-87

\begin{tabular}{|c|c|c|c|c|c|}
\hline Community & $\begin{array}{l}\text { Start } \\
\text { Date }\end{array}$ & $\begin{array}{l}\text { Host } \\
\text { Groups } \\
\text { Matched }\end{array}$ & $\begin{array}{l}\text { Refugee } \\
\text { Groups } \\
\text { Matched }\end{array}$ & $\begin{array}{l}\text { Refugee } \\
\text { Individuals } \\
\text { Matched }\end{array}$ & As At \\
\hline LONDON & $15 / 04 / 85$ & 86 & 86 & 293 & $31 / 10 / 86$ \\
\hline WINNIPEG & $15 / 03 / 85$ & 155 & 155 & 422 & $31 / 03 / 87$ \\
\hline REGINA & 29/03/85 & 59 & 71 & 181 & $28 / 02 / 87$ \\
\hline KITCHENER & $29 / 09 / 85$ & 95 & 95 & 182 & $01 / 05 / 86$ \\
\hline CALGARY & $01 / 07 / 85$ & 142 & 243 & 650 & $01 / 06 / 87$ \\
\hline VANCOUVER & $15 / 08 / 85$ & 164 & 209 & 540 & $01 / 06 / 87$ \\
\hline WINDSOR & $01 / 11 / 86$ & $\begin{array}{r}40 \\
741\end{array}$ & 40 & $120^{*}$ & $01 / 03 / 88$ \\
\hline TOTAL** & & 741 & 899 & 2,388 & \\
\hline
\end{tabular}

*estimate

**In Quebec City, between 10 August, 1985 and 1 November, 1987, seventy-four groups of refugees (211 individuals) were matched with hosts.

The two sample groups (host and control) were selected, as far as possible in each community, by matching age range, gender of household head, and mix of geographic origin so that comparisons could be made of two groups from roughly equivalent backgrounds. Overall, more than 80 per cent of the refugees in the study are male. Origins are predominantly Central American and Southeast Asian, with the European region ranking third. In three cities, London, Winnipeg and Vancouver, disproportionately more Central Americans were assigned to the host-group, while Southeast Asians predominated in the control group (See Tables $2 a$ and $2 b$ ). Family size is larger in the hosted group, with the control group representing single-person and smaller size families disproportionately (see Tables 4a and $4 b$ ).

\section{Language Acquisition}

Only those government-assisted refugees whose English language facility is judged to be insufficient for employability receive language training in English Canada. This amounts to approximately 80 per cent of both host group and control group samples. In Quebec City, the COFI French-language program is open to all adults. In principle, it was assumed that host groups would reinforce language training through informal conversation and practical experience. Such assistance is particularly an asset as the interval between arrival of the refugee and entry into a language training program could run as long as several months. The host group would in such cases launch the refugee into the rudiments of English or French.

\section{Notice}

Administrative duties as Master of McLaughlin College have imposed a demanding portion of my time and therefore, with this issue I take my leave, both as editor of Refuge and as Director of the Refugee Documentation Project (RDP). However, I shall continue to serve the RDP as Research Counsel.

I am most gratified to report that the RDP Board of Directors found a successor, unanimously choosing Howard Adelman. Professor Adelman returns from a highly successful research leave, during which his work on the never-before-accessed UNRWA files has resulted in a complete manuscript for publication and a data base large enough to double the size of RDP's present Resource Centre holdings. Howard will be leading a newly invigorated constellation of qualified researchers and practitioners on a challenging longrange e:qquiry into the global refugee crisis. This will involve academics and practitioners in a series of colloquia devoted to this topic, according to their area of expertise.

Also with this issue, and due to increasing research duties, Noreen Spencer-Nimmons will take leave as Managing Editor of Refuge. Alex Zisman, who served as Features Editor through 1986, will return as both Features and Managing Editor. His experience with refugee situations, especially in the Latin American context, has already been evident in these pages. He will continue the tradition of critical enquiry and faithful reporting which have been engendered by all the RDP and Refuge staff through these seven volumes.

I wish to thank the Members of the Board, Guest Editors, and the RDP staff for their indispensible service to Refuge this year. I have enjoyed and been inspired during my term as Editor and Director by the work which we have shared together: it has been truly a collective effort.

And most of all in our work together, we thank our readers for their continued interest and support.

C. Michael Lanphier

Cont'd on page 4 
TABLE 2a - Regional Origins of Host-Group and "Control" Refugees in Kitchener, London and Winnipeg (a)

Kitchener London

\begin{tabular}{lcccccc} 
& \multicolumn{2}{c}{ Kitchener } & \multicolumn{3}{c}{ London } & \multicolumn{2}{c}{ Winnipeg } \\
Region & Host.G. & Ctrl.G. & $\begin{array}{c}\text { Host.G. } \\
\text { Host.G.Ctrl.G. }\end{array}$ & Ctrl.G. & \multicolumn{2}{c}{ Host. } \\
Europe & 4 & 9 & 1 & 2 & 5 & 9 \\
Middle East & 1 & 1 & 0 & 0 & 0 & 1 \\
S.E. Asia & 18 & 7 & 6 & 15 & 11 & 17 \\
C. America & 11 & 4 & 26 & 12 & 16 & 7 \\
Cuba & 1 & 0 & 1 & 0 & 0 & 0 \\
S. America & 0 & 0 & 1 & 0 & 2 & 1 \\
Not Stated & 0 & 4 & 0 & 0 & 1 & 0 \\
Total & 35 & 25 & 35 & 29 & 35 & 35
\end{tabular}

Notes: (a) No control Group in Quebec City. There, regional origins of the thirty-five Host Group assisted refugees were Europe 8, S.E. Asia 15, and Not Stated 2.

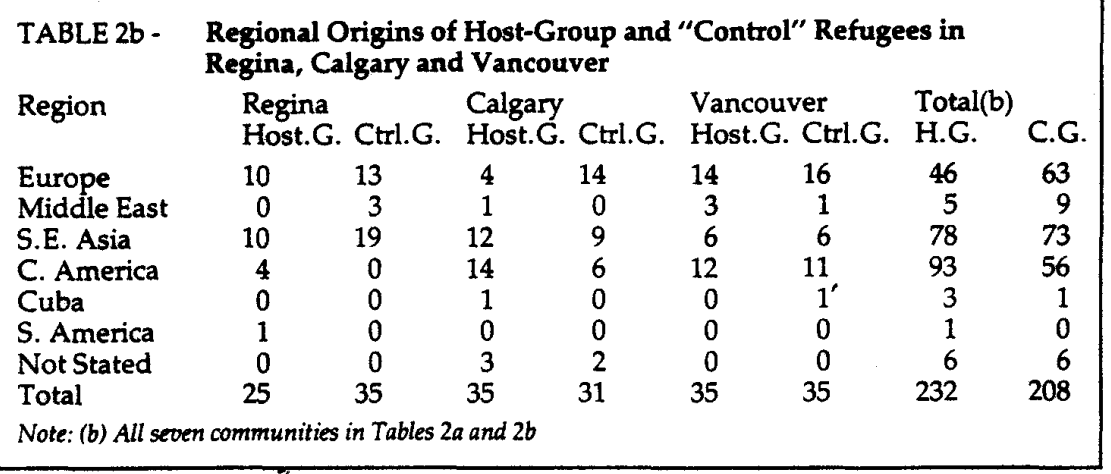

\section{Host Family Update.... Cont'd from page 3}

Data on language acquisition show three benefits of the host group program. First, retention in the Language program was higher among host group refugees. Only 4 per cent of the host group dropped out of language training, as compared with 12 per cent of the control group refugees. Most "dropouts" occurred when a job was landed. In the case of host group refugees in Quebec City, there was apparently no dropout, although one refugee's language was judged sufficiently high not to enrol. It may be stated then that in the short run, some control group refugees were more successful in landing employment early. Such success invariably occurs at the expense of longer-term job chances which usually depend upon a certain level of competence in English.

Secondly, somewhat more change in language ability occurred among host group refugees. As indicated in Table 3 , about 60 per cent of the host group refugees across five English-speaking communities showed marked improvement ( 2 levels or greater), compared with 56 per cent among the control group refugees over a 12 month period. In Quebec City, fully 80 per cent of the hostgroup refugees rose at least 2 levels in proficiency, according to reports of CEC counsellors. Thirdly, a good command of English (or French) is crucial in the facilitation of both social and economic goals of refugees. English- or French-speaking host groups facilitated learning the language to which host-group refugees aspired. Several control group refugees when interviewed expressed frustration at not being able to advance in their job and economic aspirations because of inadequacy in language skills. By contrast, refugees matched with host groups developed language skills rapidly while sustaining social relationships with their

\begin{tabular}{|c|c|c|c|}
\hline \multicolumn{4}{|c|}{$\begin{array}{l}\text { TABLE } 3 \text { - Language Ability Change of } \\
\text { Host-Group and "Control" } \\
\text { Refugees First } 12 \text { Months (c) }\end{array}$} \\
\hline & $\begin{array}{l}\text { Host } \\
\text { Group }\end{array}$ & $\begin{array}{l}\text { Control } \\
\text { Group }\end{array}$ & Total \\
\hline $\begin{array}{l}\text { No Change } \\
1 \text { LEVEL } \\
2 \text { LEVELS } \\
3 \text { LEVELS } \\
4 \text { LEVELS } \\
\text { Unknown } \\
\text { Total }\end{array}$ & $\begin{array}{r}15 \\
40 \\
62 \\
21 \\
0 \\
27 \\
165\end{array}$ & $\begin{array}{r}18 \\
38 \\
53 \\
16 \\
1 \\
39 \\
165\end{array}$ & $\begin{array}{r}33 \\
78 \\
115 \\
37 \\
1 \\
66 \\
330\end{array}$ \\
\hline
\end{tabular}
hosts. Such initial successes motivated refugees to improve their language skills even further. Thus the social benefits of language acquisition through the assistance of facilitator host groups appear to be significant and newcomers gain confidence when approaching other Canadians in job-related or other aspects of daily life.

\section{AAP Contributions*}

At the end of the one year study of the Adjustment Assistance Program (AAP), almost all clients had exhausted the benefit period. There was only a slight difference in the per-person or per-week contributions according to host group or control group. Overall, a higher percentage of the control group (40\%) received per-person payments in excess of $\$ 2600$, compared with 32 per cent for the host group refugees. In Kitchener, Calgary and Vancouver, host-group refugees received AAP for longer periods than did control group refugees. But more host group refugees eventually became employed than did control group refugees, so that the net difference in total AAP payments between control and host group refugees in those three communities cancelled out.

Host groups were cautioned not to give or loan money to refugees. Yet Host Group co-ordinators report that host group refugees were given a wide array of amenities: colour TV, kitchen appliances, extra furniture and clothing.

${ }^{*} Q u e b e c$ equivalent data of AAP not included in the evaluation.

\section{Employment}

In Kitchener, Calgary, and Vancouver, some control group refugees landed jobs more quickly, but by the end of the 12month period, 57 per cent more host group refugees overall had landed a first job, compared with 53 per cent for control group refugees, and with considerable variation in the rate of employment across the six local job markets. In Quebec City, only four host-group refugees had landed jobs by the end of the year.

Among those employed, there appeared no differences between host group and control group refugees in sources of job referrals. Overall, about half the refugees in both groups used CEC services as the main job source, although those in Kitchener and Calgary were far more self-reliant in finding their first job. While the direct effect of host groups in locating jobs appears minimal, there are impor- 
tant indirect effects. Refugees with host groups received more assistance in developing a concrete and realistic orientation to the job market. In the evaluation interview, they expressed higher levels of employment aspirations as well as a certain optimism about their progress. By contrast, refugees in the control group expressed despair over not being able to land a job or, if successful, over finding some hope of advancement.

\section{CEC Involvement}

A prime objective of the host group program was to relieve CEC counsellors from day-to-day assistance with meeting the refugees' needs and to conserve counsellors' time for instances requiring sustained and professional intervention. The pilot program overall reveals no clear differences between the host group and control group in terms of the number of visits of a refugee to the CEC (Canada Employment Centre) offices. Most counsellors, however, reported a "positive effect" of the host group experience upon refugees: assistance of the host group was usually sought before approaching the CEC counsellor.

\section{Relocation}

After the first year, 30 per cent of the control group refugees moved away from London, Winnipeg and Regina, in comparison with only 6 per cent of those in host groups who moved away, primarily to Toronto. By contrast, only about 6 per cent of refugees of either group in Quebec City, Kitchener, Calgary and Vancouver, relocated. The reasons for relocation varied; about half indicated their interest in joining family or friends, while refugees matched with host groups indicated that they had formed close friendships in their communities and were getting settled, especially in the job market.

\section{Social Adaptation}

Refugees indicated in interviews that difficulties in adjusting to life in Canada continued even after one year's residence. But those refugees attached to host groups expressed much satisfaction with having special assistance in a variety of instances, and ranging from general support to specific assistance in shopping, preparing correspondence and searching out services in the community. Invariably in an emergency, persons in the host group were a principal resource. They would spend many hours in informal counselling or giving direct assis-

TABLE 4a - Family Size of Host-Group and "Control" Refugees in Quebec City, Kitchener, London and Winnipeg

$\begin{array}{llll}\text { Family } & \text { Quebec City } & \text { Kitchener } & \text { London } \\ \text { Size } & \text { Host.G. } & \text { Host.G. Ctrl.G. } & \text { Host.G. Ctrl.G. Hinnipeg } \\ & & \text { Host.G. Ct }\end{array}$

Size Host.G. * Host.G. Ctrl.G. Host.G. Ctrl.G. Host.G. Ctrl.G

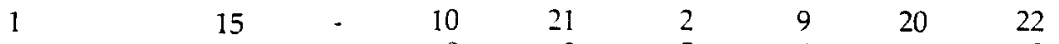

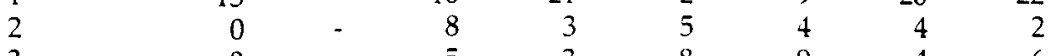

$\begin{array}{lllllllll}3 & 8 & - & 5 & 3 & 8 & 9 & 4 & 6\end{array}$

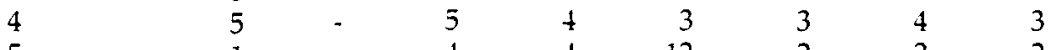

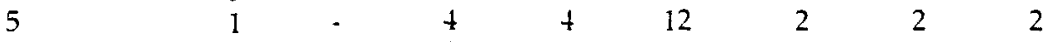

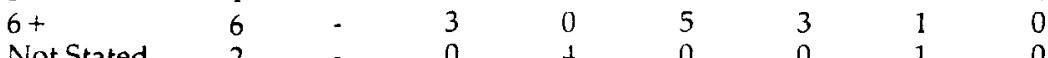

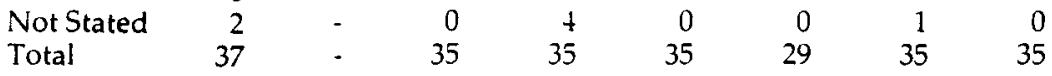

"No "control" Croup in Queter Cily

TABLE 4b - Family Size of Host-Group and "Control" Refugees in Regina, Calgary and Vancouver

\begin{tabular}{lcrrrrrrr} 
Family & Regina & \multicolumn{3}{c}{ Calgary } & \multicolumn{2}{c}{ Vancouver } & \multicolumn{2}{c}{ Total** } \\
Size & Host.G. & Ctrl.G. & Host.G. & Ctri.G. & Host.G. & Ctrl.G. & H.G. & C.G. \\
1 & 8 & 25 & 10 & 12 & 10 & 9 & 75 & 98 \\
2 & 3 & 3 & 4 & 6 & 4 & 4 & 28 & 22 \\
3 & 3 & 4 & 7 & 5 & 9 & 3 & 44 & 30 \\
4 & 5 & 3 & 4 & 5 & 9 & 15 & 35 & 33 \\
5 & 4 & 0 & 6 & 2 & 3 & 2 & 32 & 12 \\
$6+$ & 2 & 0 & 4 & 1 & 0 & 2 & 21 & 5 \\
Not Stated & 0 & 0 & 0 & 0 & 0 & 0 & 3 & 4 \\
Total & 25 & 35 & 35 & 31 & 35 & 35 & 238 & 204
\end{tabular}

**All seten communities in Tables 4 a and th

tance, far more time than could be afforded by any agency counsellor.

The control group refugees felt less. well accepted and were less well acquainted with neighbours than were those who had been hosted. Perspectives toward the future likewise contrasted: control group refugees saw little promise and they sometimes despaired. Refugees with host group experience related stories of personal assistance in cases of illness, pleasant interludes of hospitality, and of friendly, unrestrained assistance.

\section{Community Awareness}

Spontaneous comments by hosts and programme coordinators indicate an important benefit from the host group operation: a positive impact upon the local community in a wide variety of situations. First, the publicity of the program heightens awareness of persons and groups at a slight remove from hosts: e.g., members of the same faith or community group; or friends and neighbours of host families themselves. Consequently, invitations for presentations to local community functions, in classrooms and on community TV all resulted in a wider community awareness of the situation of refugees in general, and of the Host Group Program in particular.

Secondly, members of host groups state that assisting refugees becomes a lesson in appreciation. They witness the sheer difficulties of everyday struggles for existence among people made suddenly poorer and more dependent on others. The program stimulates positive helping attitudes while the feedback on the process of social amelioration in general has a positive effect on both host and refugee partners.

In London, Regina and Vancouver refugees were matched with host groups within one week of their arrival in Canada, but in Winnipeg, Calgary and Kitchener matched refugees with host groups did not occur for several weeks. In all areas of the study, the impact of the host group could only be diminished, the longer the time period between arrival and matching.

Owing to different times of arrival of refugees and staging of the evaluation, the "after 12 months" evaluation criterion was made more flexible in this report. In Regina and Calgary, the lapse of time between arrival and "year-end" evaluation was far shorter than 52 weeks. In Kitchener and Winnipeg, the period of time between arrival and evaluation was often considerably longer.

All areas of the analysis are thereby affected. Refugees in the "control" group would not have had the same opportunity to show signs of adaptation as would those in the host group condition. Among the differences, a sample group that has been in the country longer will

Cont'd on page 6 